\title{
Energy Evolution Law of Ore-Bearing Rock during Unloading under High Static Stress and Frequent Disturbance
}

\author{
Chun Wang $\mathbb{D}^{1,2,3,4}$ Mei-zhi Xie $\mathbb{D}^{1,},{ }^{2,5}$ Zu-qiang Xiong $\mathbb{D}^{1},{ }^{1}$ Cheng Wang $\mathbb{D}^{1,3}$ \\ and Lu-ping Cheng $\mathbb{D D}^{1,3}$ \\ ${ }^{1}$ School of Energy Science and Engineering, Henan Polytechnic University, Jiaozuo, Henan 454000, China \\ ${ }^{2}$ Guangxi Key Laboratory of Disaster Prevention and Engineering Safety, Guangxi University, Nanning, Guangxi 530029, China \\ ${ }^{3}$ State and Local Joint Engineering Laboratory for Gas Drainage \& Ground Control of Deep Mines, Henan Polytechnic University, \\ Jiaozuo, Henan 454000, China \\ ${ }^{4}$ The Collaborative Innovation Center of Coal Safety Production of Henan, Jiaozuo, Henan 454000, China \\ ${ }^{5}$ College of Civil Engineering and Architecture, Guangxi University, Nanning, Guangxi 530029, China
}

Correspondence should be addressed to Mei-zhi Xie; xmzgxdx@163.com,Zu-qiang Xiong; 47827889@qq.com, and Cheng Wang; 23754987@qq.com

Received 26 April 2020; Accepted 29 June 2020; Published 9 October 2020

Academic Editor: Dimitri Volchenkov

Copyright (c) 2020 Chun Wang et al. This is an open access article distributed under the Creative Commons Attribution License, which permits unrestricted use, distribution, and reproduction in any medium, provided the original work is properly cited.

Based on the complex engineering environment in deep rock engineering, preloaded high axial pressure, unloading of axial pressure, and impact loading were used to simulate high in situ stress, unloading of excavation, and blasting disturbance, respectively; the experimental study on frequent impact disturbances under unloading of high static load was carried out, which aimed at revealing the energy evolution law of rock. First, the equations of elastic property, plastic energy, and incident energy in the impact process are discussed by theoretical analysis. Then, it is found by further investigation that dynamic stress-strain curve and envelope curve of rock are with the same change tendency. The initial stage was short straight stage, and then linear stage appeared and was less influenced by unloading rate. The plastic energy, the ratio of reflected energy to incident energy, and the energy consumption per unit volume of rock increase during impact. The higher the preloaded axial pressure is, the greater the ratio of reflected energy to incident energy is, the smaller the ratio of transmitted energy to incident energy and the average energy dissipation per unit volume of rock are. When the unloading rate increased, the elastic energy generated by impact gradually increased, the plasticity gradually weakened, the ratio of transmitted energy to incident energy increased, and the ratio of reflection energy to incident energy decreased.

\section{Introduction}

Due to the continuous progress of human society, the demand for all kinds of mineral resources is gradually expanding, and because the Earth's shallow mineral resources gradually tend to run out with the mining over the years, the exploration and mining of deep mineral resources to meet the needs of human economic development will be an important way to replenish mineral resources in the future $[1,2]$. However, the high in situ stress, blasting excavation and other frequently disturbed mechanical environment in deep mining have a serious impact on the excavation, support, and other rock mass engineering. If the prevention and treatment is not appropriate, rock burst, large area collapse, and other safety accidents may be caused $[3,4]$. In particular, rock burst accidents often occur in deep tunnel excavation, which directly threatens the safety of construction personnel and equipment. In order to solve this problem, scholars have also studied the mechanical characteristics of deep granite and put forward some intelligent optimization methods for chamber excavation $[5,6]$. At the same time, the mechanism and prevention and control technology of rock burst in deep tunnel are also discussed. It is found that the evolution law of energy in rock mass is the 
main index to reveal the mechanism of rock burst $[7,8]$. Therefore, it is urgent to study the mechanical characteristics of deep rocks in complex environments, especially the dynamic characteristics under dynamic impact and disturbance loads, and to seek theoretical support for the stability control of deep rocks. Moreover, the energy is an internal factor of material deformation and failure. It is an effective way to reveal the damage, fracture, and instability mechanisms of deep rock in complex environmental conditions to study the evolution law of energy in rock deformation and failure process [9-11]. For example, Duan et al. $[12,13]$ revealed the influence of loading path on the failure characteristics of surrounding rocks by analyzing the relationship between rock accompanying energy and damage deformation in triaxial cyclic loading test. The research provide a theoretical basis for the selection of mechanical parameters for the excavation of deep underground rock mass engineering.

At present, the dynamic characteristics of deep rocks under high in situ stress have been studied by scholars in the field of rock mechanics. For example, the improved SHPB test system was used to carry out dynamic mechanics tests of deep rocks, and it was found that the dynamic compressive strength of deep rocks increased with the increase of burial depth or lateral pressure coefficient [14-16]. At the same time, it is found that the number of cracks in rock increases with the increase of loading strain rate under the impact load, and the failure mode is mostly compression shear failure [17, 18]. But the equilibrium state of the original rock stress will be broken when the deep rock mass is excavated by the blast or other methods. In the process of forming a new stress equilibrium environment, the load of ore rock on working surface increases and decreases. Based on this, scholars believe that the deformation law of rock in the unloading process is of more engineering practice significance, so the mechanical test of deep rock during unloading was carried out by them [19-22]. For example, by studying the mechanical characteristics of deep rock considering prepeak unloading damage, it is found that the static and dynamic macroscopic mechanical parameters of the rock decrease with the increase of damage variables, and the final failure mode of the rock also shows some differences when the unloading rate is different [23-25]. When the rock is in the process of unloading under high stress, with the increase of unloading rate, the macroscopic fracture property of rock develops from shear and tensile shear composite to tensile splitting [26, 27]. As for revealing the damage and failure mechanism of deep rocks by studying the evolution law of accompanying energy during the experiment, some scholars have also carried out a discussion. For example, it is found that the dissipated energy and absorbed energy of rock increase with the increase of strain rate and confining pressure under impact load [28-31]. Under dynamic and static combination loading, when the incident energy is the same, the dynamic compressive strength of rock increases first and then decreases with the increase of preloading static load, and the fracture mechanism is transformed into shear/tensile equivalent from tensile-dominated mixed mode [32-36]. By studying the influence of moisture content on energy consumption of rock under dynamic load, it is found that the larger the water content is, the smaller the energy storage capacity of the rock is, and the more likely it is to produce crushing damage [37-39]. In summary, scholars not only studied the dynamic characteristics of deep rocks with different depths, high stress, and unloading rate but also analyzed the evolution law of rock accompanying energy under various conditions and effectively revealed the damage and failure mechanism of rocks in the corresponding environment. However, based on deep rock engineering practice, the study on the law of energy evolution of rock subjected to excavation blasting and other frequent disturbances during high static load unloading is still insufficient.

In order to keep in line with the actual stress environment experienced by ore rocks during the deep rock mass engineering construction, the skarn with a buried depth of about $900 \mathrm{~m}$ was selected to carry out frequent impact disturbance tests for high static load unloading, so as to study the evolution law of rock accompanied by various energies in the course of the experiment. At the same time, the relationship between internal elastic energy, plastic energy, energy dissipation per unit volume, and rock damage degree is also discussed, and the failure mechanism of rock is revealed from the energy point of view, so as to provide theoretical basis for mining, support, and disaster prediction in deep rock mass engineering construction.

\section{Test Preparation}

\subsection{Test Rock Sample and Equipment}

2.1.1. Test Rock Sample. The test core was taken from the surrounding rock near the mine exit roadway at a depth of $900 \mathrm{~m}$ in the underground of Dongguashan copper mine. According to the analysis, the core was skarn contained a small amount of cooper ore, and its color was light gray or dark gray green with nonuniform crack defects and point star copper minerals on the surface, but the overall structure is dense and the homogeneity is good. According to the requirements of rock mechanics test, the specimens were processed into two kinds of diameters $(50 \mathrm{~mm} \times 100 \mathrm{~mm}$ and $50 \mathrm{~mm} \times 50 \mathrm{~mm}$ ) to ensure the accuracy of the test results. The specimens with high diameter ratio of $2: 1$ were used to measure the uniaxial compressive strength, while the specimens with a high diameter ratio of $1: 1$ were used to dynamic test. Furthermore, the specimens with same density were selected for test to ensure that the copper content is similar, and the nonparallelism and nonperpendicularity of both sides of the rock sample should be less than $0.02 \mathrm{~mm}$. The physical drawings of two kinds of processed rock samples are shown in Figure 1.

2.1.2. Test Equipment. Instron1346 type electrohydraulic servo testing machine is used for uniaxial compressive test, and the improved SHPB test system (structure diagram as shown in Figure 2) is adopted for the high static stress and unloading test; both tests were completed in the Central South University [40-42]. As shown in Figure 2, the improved SHPB test system is mainly composed of the incident bar, transmission bar, buffer bar, heterotype impact hammer, pressure loading unit, and data acquisition system. In addition, the bars were made of $40 \mathrm{Cr}$ alloy steel with uniaxial 


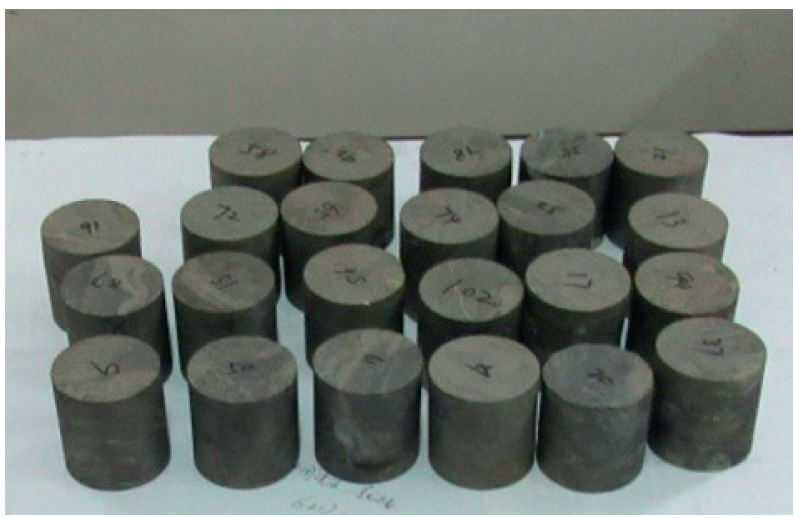

(a)

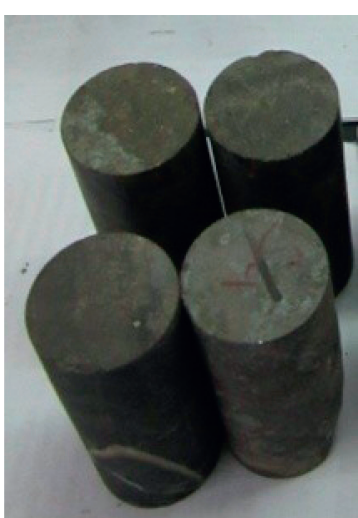

(b)

FIGURE 1: The physical picture of the processed rock sample (part of the samples): (a) Height-diameter ratio is $1: 1$; (b) height-diameter ratio is $2: 1$.

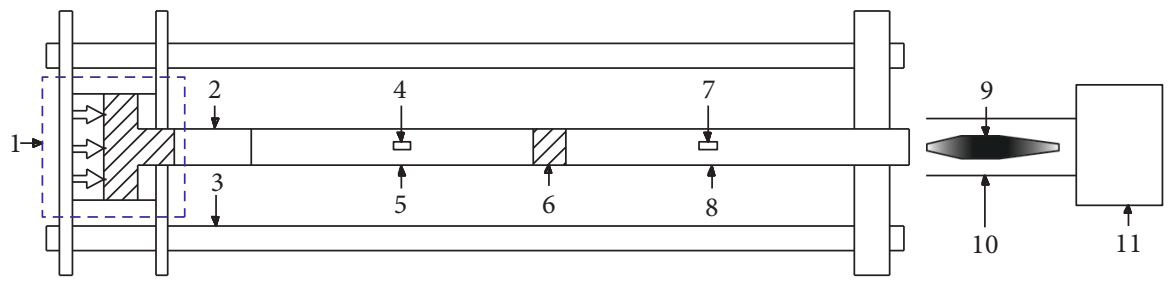

FiguRE 2: Structure diagram of the test load. 1, pressure loading unit; 2, buffer bar; 3,support; 4, strain gauge A2; 5, transmission bar; 6, rock specimen; 7, strain gauge A1; 8, incident bar; 9, heterotype impact hammer; 10, launch cavity; 11, gas gun.

compressive strength of $800 \mathrm{MPa}$, longitudinal wave velocity of $5447 \mathrm{~m} / \mathrm{s}$, and elastic modulus of $240 \mathrm{GPa}$. A high-pressure nitrogen-fired spindle-type punch is used to impact the incident bar with a length of $2 \mathrm{~m}$, which produces a half sine stress pulse of constant strain rate loading. The wave propagates through the transmitted bare with a length of $1.5 \mathrm{~m}$ and the buffer bar with a length of $0.5 \mathrm{~m}$, and part of the energy in the transmitted bar can be absorbed by the axial pressure loading device to improve test accuracy.

2.2. Test Principle. According to the principle that the elastic wave propagates in the slender bar without distortion under one-dimensional stress and the stress or strain at the interface between the specimen and bar tends to balance after many reflections, the strain gauges $A_{1}$ and $A_{2}$ posted on the incident and transmitted rods can measure the voltage signals corresponding to the incident, reflected, and transmitted waves in the process, respectively. Then, the measured voltage signal had been converted into the corresponding incident stress, reflection stress, and transmitted stress, and the dynamic stress, dynamic strain rate, and dynamic strain of the specimen can be deduced according to the following formula [43]:

$$
\begin{gathered}
\sigma_{s}(t)=\frac{A}{2 A_{S}}\left[\sigma_{I}(\mathrm{t})+\sigma_{R}(t)+\sigma_{T}(t)\right], \\
\dot{\varepsilon}_{s}(t)=\frac{C}{E l}\left[\sigma_{I}(t)-\sigma_{R}(t)-\sigma_{T}(t)\right],
\end{gathered}
$$

$$
\varepsilon_{s}(t)=\int_{0}^{t} \dot{\varepsilon}_{s}(t) \mathrm{d} t
$$

where when the compressive stress is positive, $\sigma_{I}(t), \sigma_{R}(t)$, and $\sigma_{T}(t)$ are the incident stress, reflection stress, and transmitted stress during the impact, respectively; $\sigma_{s}(t)$, $\dot{\varepsilon}_{s}(t)$, and $\varepsilon_{s}(t)$ are the dynamic stress, strain rate, and strain of the specimen, respectively; $A$ and $A_{S}$ are the cross-sectional area of elastic rod and specimen, respectively; $E$ and $C$ are the elastic modulus and longitudinal wave velocity of elastic rod respectively; $l$ is the length of specimen.

2.3. Test Scheme. The purpose of frequent disturbance test during unloading with high static stress is to study the law of energy evolution in specimen under this condition. The uniaxial compressive strength of skarn is taken as a reference value, and the mean value measured for skarns is 126.63 $\mathrm{MPa}$. In order to simulate high static stress, the preadded axial pressure is set to be as close as possible to the uniaxial compressive strength of skarn, the axial pressure is unloaded at different rates to simulate the process of rock excavation, and the impact load of $0.5 \mathrm{MPa}$ is applied to simulate the condition of small disturbance. Meanwhile, the axial pressure is unloading to $50 \%$ of the preloaded axial pressure to ensure that the specimens can withstand multiple cyclic impacts. The manual hydraulic pump is used for loading before the test, and a stopwatch is used to record the loading time. When unloading, the hydraulic valve is opened 
slowly and the unloading values and unloading time are recorded to control the unloading rate.

The scheme of uniaxial compressive test is shown in Table 1, and the scheme of frequent disturbance test with high static stress during unloading is shown in Table 2.

\section{Test Results}

3.1. Stress Balance Check. Dynamic stress balance is very important in high static load unloading impact tests. Whether the stress is in equilibrium at each impact can be checked by the time-history curve of incident, reflected, and transmitted voltage. Figure 3 shows the voltage time-history curves of the 6 th, $8^{\text {th }}$, and 11 th impacts when the unloading rate is $1.50 \mathrm{MPa} / \mathrm{s}$, and the preloading axial pressure is $75 \mathrm{MPa}$

By analyzing the waveform amplitude in Figure 3, the amplitude of the incident wave is approximately equal to the sum of the amplitude of the incident wave and the reflected wave. Therefore, it can be considered that the dynamic stress in the process of impact load is balanced and the experimental data can reflect the evolution law of rock accompanying energy.

3.2. Stress-Strain Curve and Its Envelope. According to the difference of preadded axial compression and unloading rate, the specimens were divided into 16 groups. Each specimen was subjected to multiple impact disturbances, and the corresponding dynamic stress-strain can be obtained after each impact. Figure 4(a) shows some representative dynamic stress-strain curves, in which the numbers represent the impact times. To study the effect of unloading rate on dynamic stress-strain curves, the envelopes of dynamic stress-strain curves obtained from each impact were selected for analysis, as shown in Figure 4(b). Moreover, a group of representative envelope curves is listed in Figure 5 for further analyzing the change trend of the envelope of dynamic stress-strain curves.

It can be seen from Figure 4(a) the initial stages of the dynamic stress-strain curves are the short linear segments, and they enter into the nonlinear stages soon. It shows that the specimens during unloading under high static stress and impact disturbances undergo a short elastic deformation firstly and then turn into plastic deformation stage. The microcracks in specimen are completely closed because of the prehigh axial pressure, so the specimens enter the elastic stage directly with unloading and impact disturbances. Furthermore, the prehigh axial pressure causes damage to the specimen during loading and unloading, which makes the specimen pass into the plastic deformation stage after a short period of elastic deformation.

As shown in Figure 4(b), the change trend of the envelope of dynamic stress-strain curves is consistent with that of the dynamic stress-strain curve during each impact, and the envelope reflects the whole process change trend of specimen with multiple impact disturbances under same axial pressure, same unloading rate, and same impact strength.
The change trend of envelope curve is consistent under the same axial compression in Figure 5, which goes through a short straight line segment firstly and then enters the nonlinear development stage, indicating that the dynamic change trend of rock is less affected by unloading rate. In Figure 5, $118 \mathrm{MPa}, 117 \mathrm{MPa}, 115 \mathrm{MPa}$, and $113 \mathrm{MPa}$ are the corresponding peak dynamic stresses when the unloading rates are $0.5 \mathrm{MPa} / \mathrm{s}, 1.0 \mathrm{MPa} / \mathrm{s}, 1.5 \mathrm{MPa} / \mathrm{s}$, and $2.0 \mathrm{MPa} / \mathrm{s}$, separately, and the range of their difference varies from $0.85 \%$ to $4.24 \%$, showing a decreasing trend. It indicates that the dynamic stress in specimen decreases with the increasing unloading rate, which is beneficial to enhancing stability.

3.3. Failure Mode. The final failure pattern of the rock sample can also reflect the stress state of the rock sample and the variation law of internal energy. Figure 6 shows a set of typical rock sample failure patterns.

As shown in the figure, when the axial static pressure is the same, the ultimate rock failure lumpiness decreases gradually with the decrease of the axial unloading rate. It is caused by the long time of axial pressure, the full development of internal microcracks, and the increase of damage accumulation. By further analyzing the shape of the rock block in the figure, it can be found that most of the rock blocks are striped, and this indicates that the fracture along the axial direction of the rock sample produces tensile failure. At the same time, the damaged rock was smooth on one side of the fracture surface without obvious scratches, indicating that the rock sample produced slip failure. Therefore, it can be concluded that the failure mode of rock is tensile slip failure.

\section{Discussion on Energy Types}

4.1. Basic Assumptions. There are many kinds of energy conversion in the unloading test under high static stress and frequent disturbance, and part of energy is difficult to calculate, such as sound energy, heat energy, energy consumption of new crack generation, and vibration energy dissipation of specimens. To study quantitatively the change law of energy in specimens before and after the impact disturbance, the conservation law of energy is discussed on the basis of certain assumption. The specific assumptions are as follows:

(1) When preloading the axial compression, it is considered that the specimen is in the stage of elastic deformation or even it is completely elastic, that is, the relationship between stress and strain obeys Hooke's law.

(2) If the preloaded axial pressure can be adjusted to the design value after each unloading and impact disturbance, it is considered that the specimen is broken incompletely, and the deformation of the specimen is small compared to its full size.

(3) If the preloaded axial pressure fails to be adjusted to the design value after each unloading and impact disturbance, it is considered that the specimen is broken completely and loses the ability to resist the external load. 
TABLE 1: Test scheme and results of deep skarn under uniaxial compression.

\begin{tabular}{|c|c|c|c|c|c|c|c|}
\hline Sample number & Height (mm) & Diameter $(\mathrm{mm})$ & Density $\left(\mathrm{g} / \mathrm{cm}^{3}\right)$ & $\begin{array}{l}\text { Longitudinal wave } \\
\text { velocity }(\mathrm{m} / \mathrm{s})\end{array}$ & $\begin{array}{l}\text { Loading rate } \\
(\mathrm{mm} / \mathrm{s})\end{array}$ & $\begin{array}{c}\text { Peak load } \\
(\mathrm{kN})\end{array}$ & $\begin{array}{c}\text { Uniaxial compressive } \\
\text { strength }(\mathrm{MPa})\end{array}$ \\
\hline XK1 & 100.02 & 50.06 & 3.78 & 5567 & 0.03 & 239.08 & 121.53 \\
\hline $\mathrm{XK} 2$ & 99.36 & 49.86 & 4.26 & 5898 & 0.03 & 384.10 & 196.82 \\
\hline $\mathrm{XK} 3$ & 99.24 & 49.56 & 4.06 & 5324 & 0.03 & 255.80 & 132.67 \\
\hline XK4 & 98.96 & 49.98 & 3.84 & 5126 & 0.03 & 176.93 & 90.23 \\
\hline XK5 & 100.02 & 50.02 & 3.72 & 5297 & 0.03 & 252.89 & 128.76 \\
\hline XK6 & 99.04 & 49.94 & 3.94 & 5135 & 0.03 & 220.17 & 112.46 \\
\hline XK7 & 100.08 & 50.04 & 3.90 & 5079 & 0.03 & 204.31 & 103.94 \\
\hline
\end{tabular}

TAвLE 2: Test scheme of skarn during unloading under high static stress frequent disturbances.

\begin{tabular}{|c|c|c|c|c|c|c|c|c|}
\hline $\begin{array}{l}\text { Sample } \\
\text { number }\end{array}$ & $\begin{array}{l}\text { Height } \\
(\mathrm{mm})\end{array}$ & $\begin{array}{l}\text { Diameter } \\
(\mathrm{mm})\end{array}$ & $\begin{array}{l}\text { Density } \\
\left(\mathrm{g} / \mathrm{cm}^{3}\right)\end{array}$ & $\begin{array}{l}\text { Longitudinal wave } \\
\text { velocity }(\mathrm{m} / \mathrm{s})\end{array}$ & $\begin{array}{c}\text { Preaxial } \\
\text { pressure } \\
(\mathrm{MPa})\end{array}$ & $\begin{array}{l}\text { Axial pressure } \\
\text { on impact } \\
(\mathrm{MPa})\end{array}$ & $\begin{array}{c}\text { Unloading rate of } \\
\text { axial pressure }(\mathrm{MPa} / \\
\mathrm{s})\end{array}$ & $\begin{array}{c}\text { Impact } \\
\text { pressure } \\
(\mathrm{MPa})\end{array}$ \\
\hline XK1-1 & 50.34 & 53.60 & 3.10 & 4467 & 65 & 32.5 & \multirow{4}{*}{0.5} & \multirow{4}{*}{0.5} \\
\hline XK1-2 & 50.22 & 52.98 & 3.09 & 4549 & 75 & 37.5 & & \\
\hline XK1-3 & 49.85 & 52.88 & 3.33 & 4674 & 85 & 42.5 & & \\
\hline XK1-4 & 49.85 & 53.70 & 3.39 & 4496 & 95 & 47.5 & & \\
\hline XK2-1 & 49.47 & 53.08 & 3.56 & 4310 & 65 & 32.5 & \multirow{4}{*}{1.0} & \multirow{4}{*}{0.5} \\
\hline XK2-2 & 49.81 & 52.87 & 3.22 & 4625 & 75 & 37.5 & & \\
\hline XK2-3 & 50.05 & 53.72 & 3.53 & 4613 & 85 & 42.5 & & \\
\hline XK2-4 & 50.07 & 53.14 & 3.54 & 4428 & 95 & 47.5 & & \\
\hline XK3-1 & 49.74 & 53.15 & 3.19 & 4563 & 65 & 32.5 & \multirow{4}{*}{1.5} & \multirow{4}{*}{0.5} \\
\hline XK3-2 & 50.07 & 53.69 & 3.52 & 4146 & 75 & 37.5 & & \\
\hline XK3-3 & 49.41 & 53.20 & 3.30 & 4567 & 85 & 42.5 & & \\
\hline XK3-4 & 49.67 & 53.34 & 3.51 & 4366 & 95 & 47.5 & & \\
\hline XK4-1 & 50.30 & 53.36 & 2.94 & 4743 & 65 & 32.5 & \multirow{4}{*}{2.0} & \multirow{4}{*}{0.5} \\
\hline XK4-2 & 50.30 & 53.24 & 3.21 & 4571 & 75 & 37.5 & & \\
\hline XK4-3 & 49.71 & 53.26 & 2.85 & 4227 & 85 & 42.5 & & \\
\hline XK4-4 & 49.59 & 53.31 & 3.53 & 4252 & 95 & 47.5 & & \\
\hline
\end{tabular}

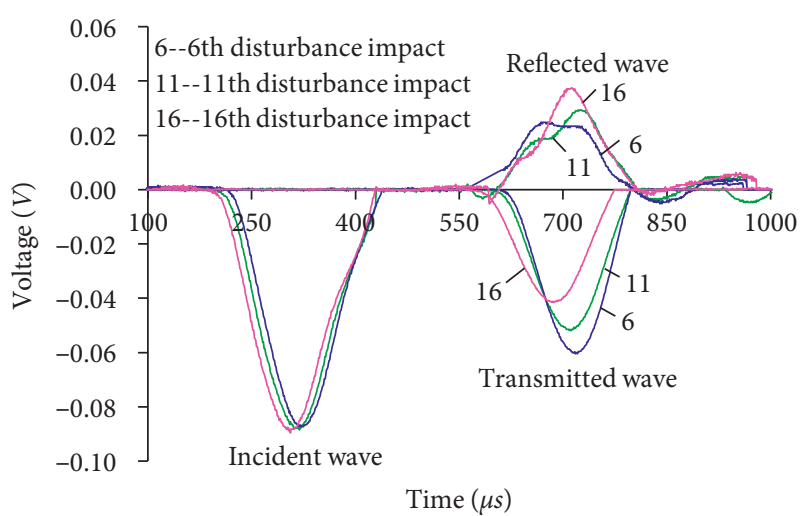

FIGURE 3: The typical voltage-time curves of rock sample during unloading under high static stress and frequent disturbance.

(4) Due to the instantaneous completion of impact disturbance, it can be assumed that there is no heat exchange between the specimen and the outside during the impact.

(5) The influence of external secondary energy can be ignored when energy is discussed, such as sound energy, air resistance energy, and vibration energy.
4.2. Energy Discussion. It was difficult to monitor the conversion law of various energies of rock during unloading under high static stress and frequent disturbances. However, the evolution law of major energies can be deduced based on some assumption, so the basic law of energy conversion in specimen can be obtained, such as elastic energy, plastic performance, release energy, and absorption. Because the specimens were subjected to multiple impact disturbances, loading, and unloading, the energy of them were changed after each impact disturbance and the types of energies before and after impact disturbances were investigated for the reliability of energy discussion.

4.2.1. Energy before the Impact Disturbance. On the basis of the assumption (1), the main energies before each impact disturbance are the elastic energy stored in specimen and the impact kinetic energy generated by the impact load, i.e., the incident energy.

(1) Elastic energy: elastic deformation occurs when the specimen is preloaded axial pressure, and a certain amount of elastic energy is stored in specimen. On the basis of assumption (1), the elastic energy stored in specimen during loading and unloading is calculated as follows: 


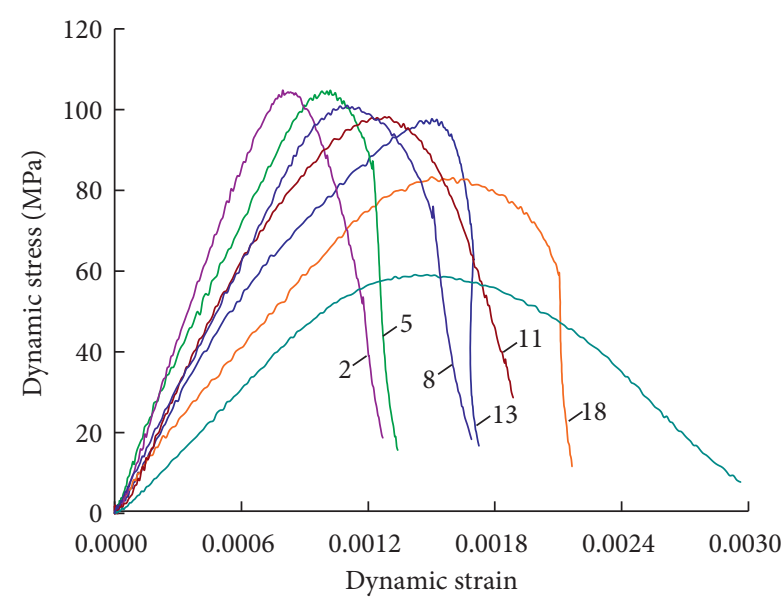

(a)

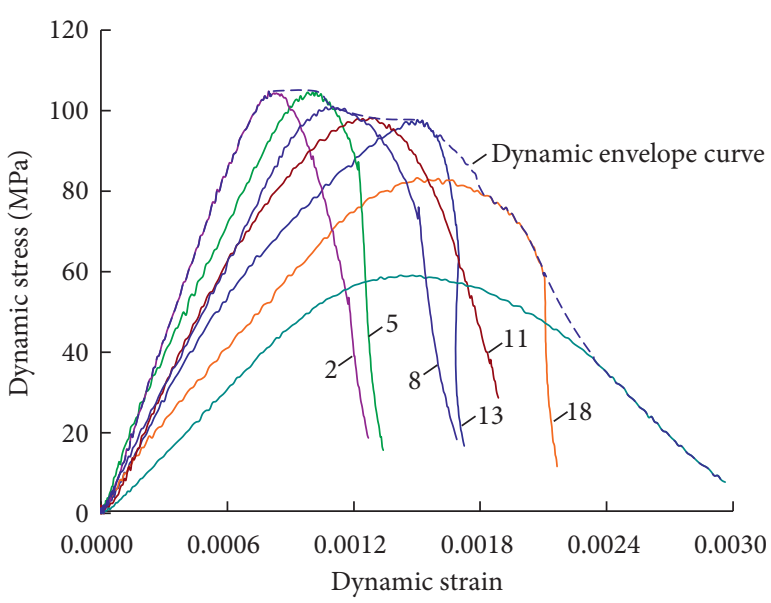

(b)

Figure 4: (a) Dynamic stress-strain curve and (b) envelope curve of skarn under the common action of high static stress unloading and impact disturbance (axial load $85 \mathrm{MPa}$; unloading rate $1.0 \mathrm{MPa} / \mathrm{s}$ ).

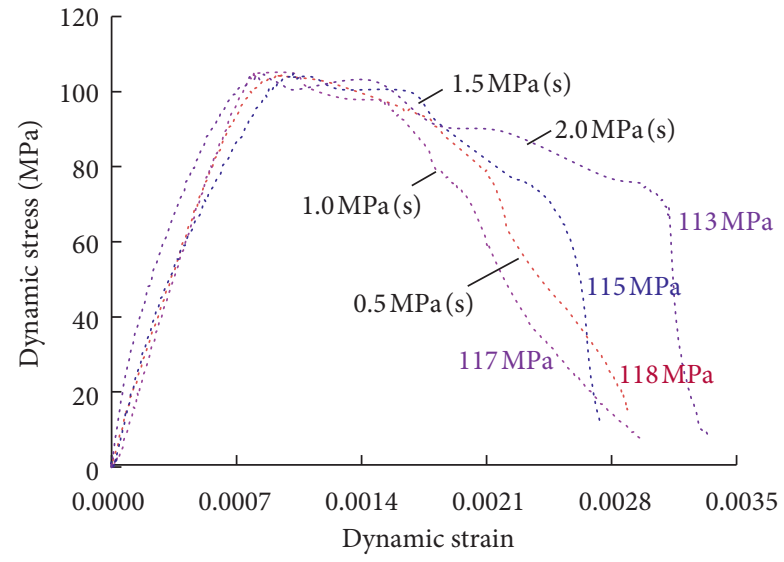

Figure 5: Dynamic stress-strain envelope curve (axial load $85 \mathrm{MPa}$ ).

$$
W_{\mathrm{tz}}=\frac{1}{2} E \varepsilon^{2} \cdot V
$$

where $W_{\mathrm{tz}}$ is the elastic energy generated by axial pressure in specimen; $E$ is the elastic modulus of specimen under static stress; $\varepsilon$ is the compressive strain of specimen; and $V$ is the volume of specimen.

The deformation of specimen obeys Hooke's law when preloading the axial compression; in addition, combined with the principle of stress and strain calculation under uniaxial compression, the formula (5) is obtained as follows:

$$
\left\{\begin{array}{l}
E=\frac{\sigma}{\varepsilon}, \\
\sigma=\frac{F_{1}}{A_{s}}, \\
V=A_{s} H .
\end{array}\right.
$$

If formula (5) is substituted into formula (4), the formula (6) can be calculated as follows:

$$
W_{\mathrm{tz}}=\frac{F_{1}^{2} H}{2 E A_{s}} .
$$

In formulas (5) to (6), $\sigma$ is the compressive stress; $F_{1}$ is the preloaded axial stress before impact disturbances; and $H$ and $A_{s}$ are the height and crosssectional area of specimen, respectively.

(2) Incident energy: sinusoidal stress wave is generated by impact of the conical punch on the incident bar during test, and the corresponding impact kinetic energy is the incident energy, which is the main source of energies required for specimens' deformation, fragmentation, rock block ejection, etc. The formula is as follows [43]:

$$
W_{I}=\frac{\mathrm{AC}}{E} \int_{0}^{\tau} \sigma_{I}^{2}(t) \mathrm{d} t
$$




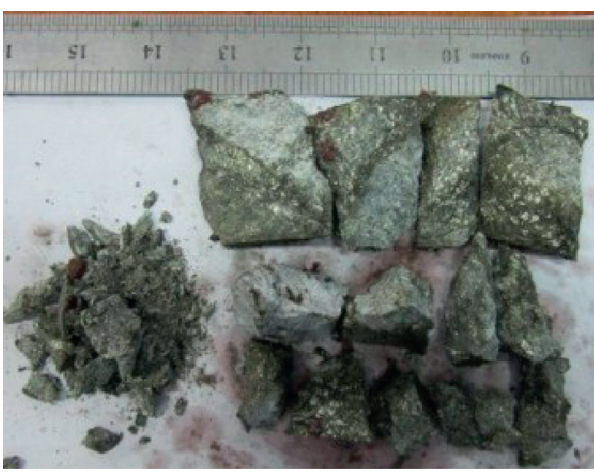

(a)

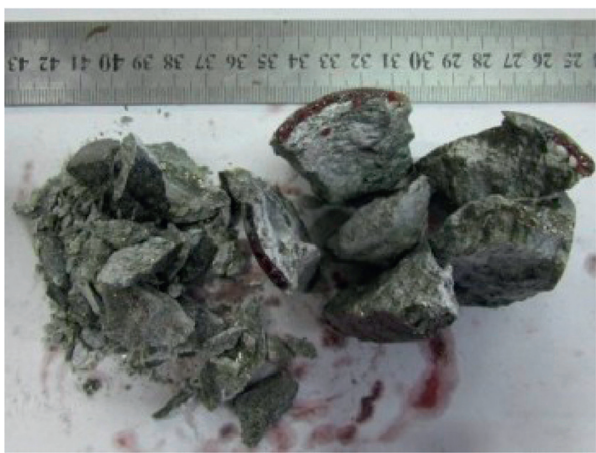

(c)

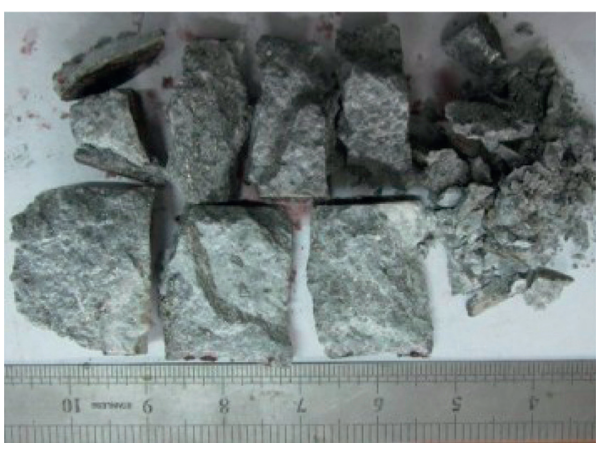

(b)

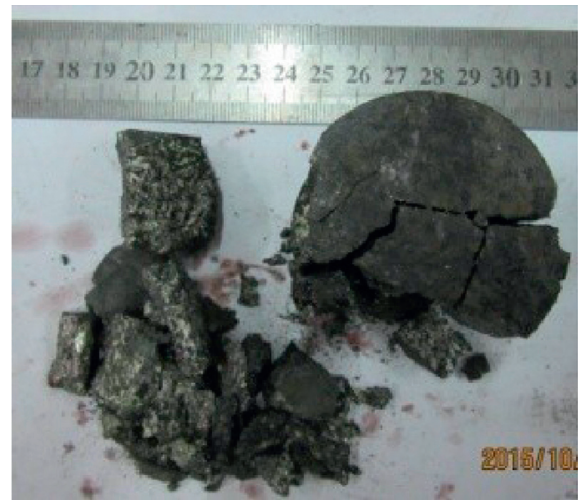

(d)

FIGURE 6: Failure mode of rock sample when preloading axial pressure is $85 \mathrm{MPa}$. Unloading rates are (a) $0.5 \mathrm{MPa} / \mathrm{s}$, (b) $1.0 \mathrm{MPa} / \mathrm{s}$, (c) $1.5 \mathrm{MPa} / \mathrm{s}$, and (d) $2.0 \mathrm{MPa} / \mathrm{s}$.

where $W_{I}$ is the incident energy; $\sigma_{I}$ is the incident stress during impact; $A, C$, and $E$ is the elastic rod cross-sectional area, longitudinal wave velocity, and elastic modulus, respectively; and $\tau$ is the duration of stress pulse.

4.2.2. Energy after the Impact Disturbance. On the basis of assumptions (1) to (4), the main energies of specimens during each impact disturbance are elastic energy, plastic energy, reflected energy, and transmitted energy. According to the law of thermodynamics, the elastic energy density $U_{i}^{e}$ and plastic property density $U_{i}^{d}$ are calculated based on dynamic stress-strain curve, and the calculation diagram is shown in Figure 7. $\sigma_{\mathrm{ps}}$ is the dynamic peak stress, $\varepsilon_{\mathrm{ps}}$ is the dynamic peak strain, and $E_{\mathrm{d}}$ is the dynamic deformation modulus in Figure $7[44,45]$.

(1) Elastic energy: when the specimen is broken completely, it is assumed that the elastic energy stored in specimen is zero on the basis of (3), so it is more meaningful to study the accompanying elastic energy of specimen that has been destroyed incompletely. In general, the elastic energy is generated by axial pressure and impact load, which can be discussed in two parts. The energy generated in specimen by the axial pressure after impact disturbance is similar to the elastic energy generated by the preloaded axial pressure before the impact, in light of hypothesis (2), which can be calculated by formula (6). The impact disturbance causes the rock sample to produce elastic deformation, and on the basis of hypothesis (2) and (4), the generated elastic energy is calculated by the following formula:

$$
W_{\mathrm{tc}}=U_{i}^{e} \cdot V=\frac{\sigma_{\mathrm{ps}}^{2}}{2 E_{d}} \cdot V .
$$

(2) Plastic energy: in the loading stage of impact stress, i.e., the stage before the peak of dynamic stress-strain curve, the elastic energy is accumulated in specimen and some energy is consumed due to the anabatic damage, so calculation formula of the total energy density $U$, in light of hypothesis (4), is as follows:

$$
\begin{aligned}
& U=U_{i}^{d}+U_{i}^{e}, \\
& U=\int_{0}^{\varepsilon_{\mathrm{ps}}} \sigma_{i} \mathrm{~d} \varepsilon_{i} .
\end{aligned}
$$

The formula (8) and the formula (10) are substituted into the formula (9), which can be obtained:

$$
U_{i}^{d}=\int_{0}^{\varepsilon_{\mathrm{ps}}} \sigma_{i} d \varepsilon_{i}-U_{i}^{e}=\int_{0}^{\varepsilon_{\mathrm{ps}}} \sigma_{i} d \varepsilon_{i}-\frac{\sigma_{\mathrm{ps}}^{2}}{2 E_{d}}
$$




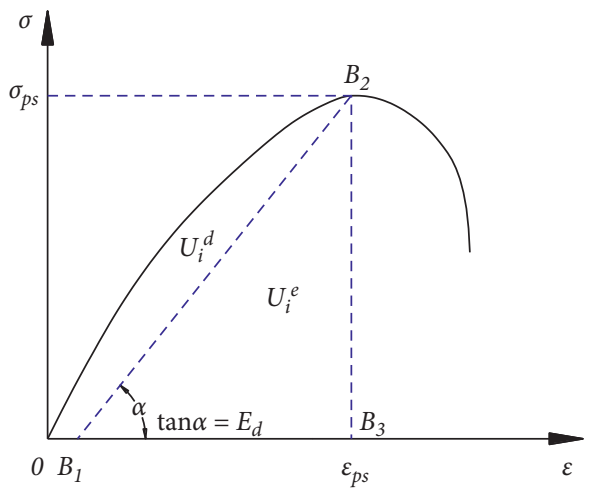

FIGURE 7: Calculation diagram of elastic energy density and plastic energy density under the common action of high static stress unloading and impact load.

The formula of plastic energy after impact disturbance is as follows:

$$
W_{\mathrm{sc}}=U_{i}^{d} \cdot V=\left(\int_{0}^{\varepsilon_{\mathrm{ps}}} \sigma_{i} d \varepsilon_{i}-\frac{\sigma_{\mathrm{ps}}^{2}}{2 E_{d}}\right) \cdot V,
$$

where $\sigma_{i}$ is the stress before the dynamic peak stress of the dynamic stress-strain curve and $\varepsilon_{i}$ is the corresponding dynamic strain of $\sigma_{i}$.

(3) Reflected energy and transmitted energy: the incident stress pulse is transmitted to the impacted surface of specimen during each impact, and part of stress pulse is reflected back from the impacted surface, that is, the associated energy is the reflected energy, while part of stress pulse continues to propagate through the specimen and the associated energy is the transmitted energy. The formulas of reflected energy and transmitted energy are as follows [43]:

$$
\begin{aligned}
& W_{R}=\frac{\mathrm{AC}}{E} \int_{0}^{\tau} \sigma_{R}^{2}(t) \mathrm{d} t, \\
& W_{T}=\frac{\mathrm{AC}}{E} \int_{0}^{\tau} \sigma_{T}^{2}(t) \mathrm{d} t,
\end{aligned}
$$

where $W_{R}$ and $W_{T}$ are the reflected energy and transmitted energy, respectively, and $\sigma_{R}$ and $\sigma_{T}$ are the reflective stress and transmitted stress in the impact process, respectively.

\section{Law of Energy Evolution}

5.1. Change Law of Elastic Energy Accompanying with Impact. In the process of high static stress and unloading, some elastic deformation occurs when the rock is disturbed by impact, which results in some elastic energy stored in rock and the ability of rock to store elastic energy reflects the internal structural state of rock indirectly. Furthermore, the change law of rock's resistance to external load can also be revealed by the elastic energy in rock during test. Figure 8 shows the relationship between the elastic energy stored in specimen and impact disturbance times, while Figure 9 expresses the change law of elastic energy with the increasing unloading rate.

In Figure 8, the elastic energy stored in specimen increases firstly and then declines with the incremental impact times, when the preloaded axial pressure is certain. Since the impact load is applied instantaneously to specimen, both the processes of energy storage and energy release exist simultaneously. During the initial several impacts, the damage degree of specimen is small and its ability to resist the external load has not been reduced significantly. Meanwhile, the compacted microcracks in specimen are recovered during the unloading of the axial static stress. This results in the increase of dynamic compression deformation of rock samples under impact loading and the increase of elastic energy stored in rock samples under impact loading with the increase of disturbance impact times. When the impact times reach a certain value, the speeds of generation, extension, and penetration of internal microcracks add rapidly, and the ability of specimen to resist external load decreases correspondingly. At this point, most of the kinetic energy generated by impact is converted into the energy consumed by generation, extension, and penetration of internal microcracks, which leads to decreasing elastic energy stored in specimen; thus, it can be inferred that the specimen is about to undergo macroscopic failure.

In Figure 9, the elastic energy is calculated based on the envelope curve of dynamic stress-strain curve, which can reflect the overall evolution state of internal energy of specimen under multiple loading, unloading, and impact disturbances. Meanwhile, the elastic energy reveals the law that the resistance of specimen to impact load is affected by the unloading rate in the test. It is also shown in Figure 9 that the elastic energy adds with the increase of unloading rate, which indicates indirectly that the energy storage capacity and the impact load resistance capacity of specimen enhance with the increasing unloading rate. The reason is that the larger the unloading rate with the fixed preloading axial pressure, the shorter the unloading time required for same axial pressure is, the shorter the time affected by high axial pressure and unloading before each impact is, and the shorter the time for microcracks to germinate and expand in specimen. Therefore, when the unloading rate is higher and the preloading axial pressure is fixed, the damage accumulation in specimen is smaller and the impact resistance of specimen is stronger. In addition, the unloading process of the axial pressure has the effect of deferring force to external impact load. When the unloading rate is higher, the deferring force effect is more obvious, resulting in the lesser effective impact stress on specimen and the cumulative fatigue damage stored in specimen after impact, that is, the specimen can store more elastic energy.

\subsection{Change Law of Plastic Energy Accompanying with Impact.} In the process of unloading and high static stress, new microcracks in specimen sprout by the impact load, and the new and old microcracks lead to the irrecoverable deformation of the specimen. With the energy consumed, the laws 


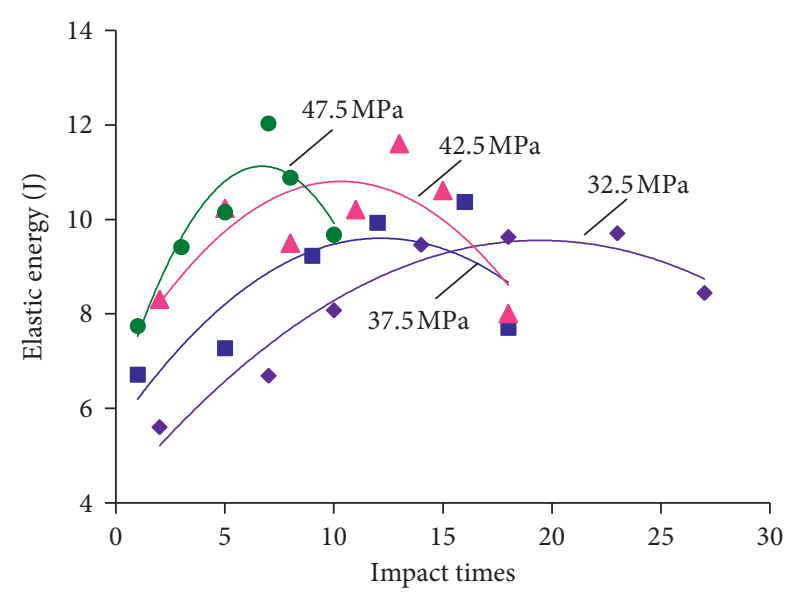

FIGURE 8: Relationship between the elastic energy accompanying with impact and impact times (the numbers in figure represents the axial static stress of specimen during impact).

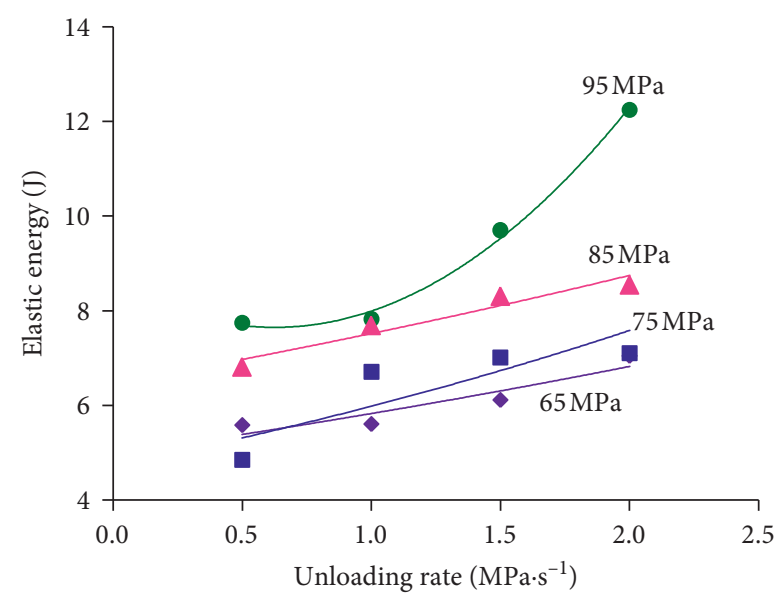

FIGURE 9: Relationship between the elastic energy accompanying with impact and unloading rate (the numbers in figure represents the preloaded axial static stress of specimen).

of the internal structure evolution of specimen can be revealed. Figure 10 shows the relationship between the plastic energy stored in specimen and impact disturbance times, while Figure 11 expresses the change law of plastic energy with the increasing unloading rate.

In Figure 10, the plastic energy accompanying with impact adds with the increasing impact times when the unloading rate is fixed. The increase of plastic energy indicates the increase of new microcracks in specimen and the acceleration of crack growth and penetration, which indicates further that frequent disturbances induces the internal aggravated damage and reduces the ability of specimen to resist external loads. It is also shown in Figure 10 that the plastic energy decreases with the increase of the axial pressure during the initial several impacts. For example, when the axial pressure value is $32.5 \mathrm{MPa}, 37.5 \mathrm{MPa}$, $42.5 \mathrm{MPa}$, and $47.5 \mathrm{MPa}$, the corresponding plastic energy of third impact is $2.56 \mathrm{~J}, 2.21 \mathrm{~J}, 2.05 \mathrm{~J}$, and $1.09 \mathrm{~J}$, respectively. This is because the preloaded axial static load is in the

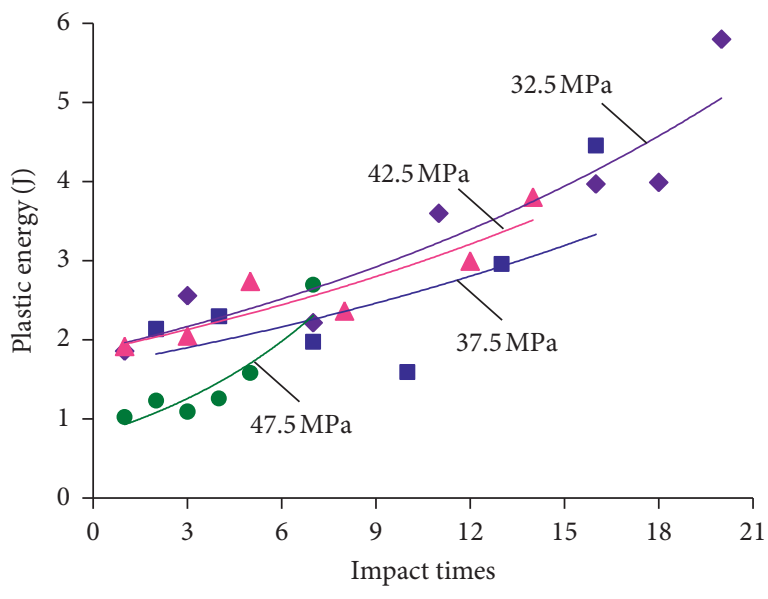

FIgURE 10: Relationship between the plastic energy accompanying with impact and impact times (the numbers in figure represents the axial static stress of specimen during impact).

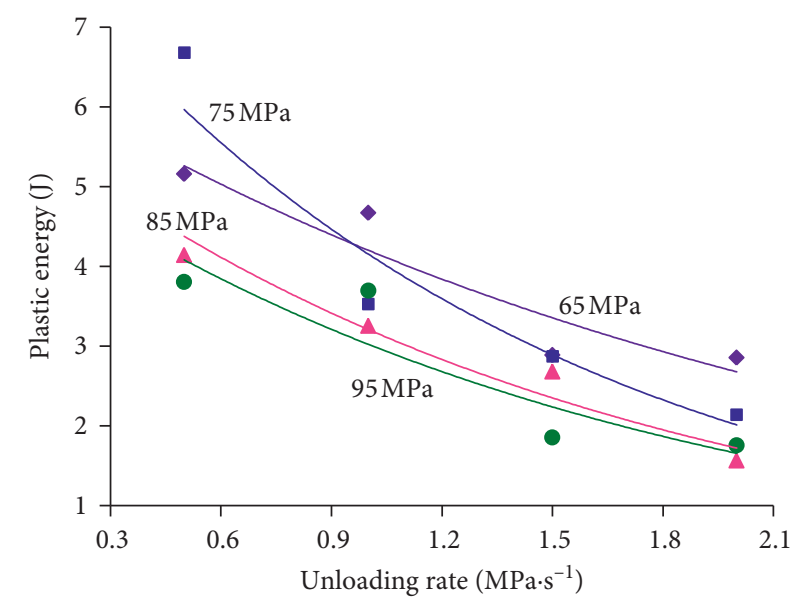

FIGURE 11: Relationship between the plastic energy accompanying with impact and unloading rate (the numbers in figure represents the preloaded axial static stress of specimen).

unloading state during impact. Although the impact is completed in a very short time, it is inevitable that the actual value of the axial static load is smaller than the design value after impact. Meanwhile, the internal damage is weak during the initial several impacts as well as the energies for germination and propagation of microcracks. The energy released by the decreasing axial static load offsets the energy required for the germination and propagation of some microcracks, which is reflected in the decline trend of the irreversible plastic energy finally.

In order to analyze the variation of rock associated plastic energy under the influence of unloading rate during the impact test, the plastic energy is calculated by using the envelope of the dynamic stress-strain curve, which can reflect the whole process of rock deformation under impact load. Therefore, it is believed that the changing law of plastic energy can also reveal the general changing trend of the internal structure of rock samples to some extent. Figure 11 shows that, when the axial static load is consistent at the 
moment of impact, the plastic energy associated with impact decreases with the increase of unloading rate. Since the duration of each impact load is the same, the larger the unloading rate is, the smaller the value of axial static load after impact is correspondingly. At this point, the number of microcracks in rock sample is small under the combined action of dynamic and static loads, and they require less energy to germinate, expand, and penetrate. This is reflected in the plastic energy change law on the trend of decreasing development. At this time, if the differences between rock samples are ignored, it can be considered that each rock sample can bear the same number of disturbance impact times, and it is further considered that the total duration of each rock sample under impact load is consistent. Therefore, it can be concluded that the plastic energy associated with impact decreases with the increase of unloading rate during the whole test process. This again shows that the unloading process of axial load has the effect of deferring force on the impact load, which is conducive to the rock's resistance to the external impact load.

\subsection{Incident Energy, Reflection Energy, and Transmission} Energy. In the process of unloading under high static load, the rock is accompanied by incident energy, transmitted energy, and reflected energy under impact load. If other energies are ignored, the incident energy is equal to the sum of reflected energy and transmitted energy. However, the unloading process, axial static load, and internal damage degree all affect the energy stored in the rock. The larger the incident energy is, the greater the impact stress on the rock sample will be. The larger the transmitted energy is, the denser and more homogeneous the rock sample is. The larger the reflection energy is, the more serious the damage in the rock sample is. At the same time, factors such as sound, temperature, and friction are considered to affect the three energies. In order to reduce the error effect, the variation law of the ratio of reflected energy and transmitted energy to incident energy is analyzed, and the structural characteristics of the rock sample in the process of unloading under impact load can be more accurately reflected, as shown in Figures 12 and 13.

Figure 12 shows that, when the unloading rate or the preloaded axial pressure is constant, the ratio of reflected energy to incident energy increases with the increases in the disturbance impact times. This indicates that, during the unloading process, when rock is subjected to the impact load, the internal crack germination increases gradually and the crack width and length also increase gradually, resulting in the decrease of rock density. At this point, the resistance of the stress wave to continue to propagate through the rock sample increases, some cracks will germinate at the impacted end of rock sample, and the total area of reflected stress wave will be increased accordingly under impact load. Therefore, when the value of the impact load is constant, the proportion of reflected energy increases with the increase of the disturbance impact times. Further analysis shows that, the greater the preloaded axial pressure, the greater the ratio of reflected energy to incident energy, as shown in Figure 12(a).
This indicates that the preloaded high axial pressure also leads to certain damage in the rock, which also increases the total area of reflected stress wave. In Figure 12(b), when the preload axial pressure is constant, the larger the unloading rate is, the smaller the ratio of reflected energy to incident energy is. The reason is that the deferring force effect of the unloading process on the external impact load can help to reduce the damage of rock sample under the impact load. Meanwhile, the force recoil effect also consumes part of the energy reflected from the rock sample section, resulting in the decrease of the total reflected energy and the proportion of the reflected energy in the incident energy.

Figure 13 shows that, when the unloading rate or the preloaded axial pressure is constant, the ratio of transmitted energy to incident energy decreases with the increases of the disturbance impact times. The more the cracks in the rock, the more difficult it is for the stress wave to continue to propagate, and the smaller the total energy of the stress wave propagating through the rock sample under the impact load of the same strength. Therefore, the change rule of the ratio of transmitted energy to incident energy decreases with the increase of the disturbance impact times reveals that the damage of the rock gradually intensifies and resistance to external impact load gradually decreases with the increase of impact times. It is found that the ratio of transmitted energy to incident energy decreases with the increase of preloaded axial pressure by analysis of the influence of preloaded axial pressure on the variation of transmitted energy, as shown in Figure 13(a). This indicates that the axial pressure of preloading to some extent aggravates the damage in the rock. It is found that the ratio of transmitted energy to incident energy increases with the increase of unloading rate by analysis the influence of unloading rate on the variation of transmitted energy, as shown in Figure 13(b). This phenomenon reveals that the unloading process of axial static load is conducive to weakening the impact load, and it can also be considered that the rock's ability to resist the external impact load is enhanced during unloading under high static stress and frequent disturbances. As a result, the damage degree of the rock sample is weakened under the impact load of the same strength, and then the stress wave effect that continues to propagate through the rock sample is enhanced.

5.4. Energy Dissipation per Unit Volume of Rock Sample. In the process of high static load unloading, the internal damage degree of rock sample under impact load can also be characterized by energy dissipation per unit volume of rock sample. The more energy the rock consumes, the more severe the internal microcracks are, and the more serious the damage is. According to the difference between incident energy, reflected energy, and transmitted energy during the test, the consumption of external energy of rock sample can be deduced. The calculation formula is as follows:

$$
W_{V}=\frac{W_{I}-\left(W_{R}+W_{T}\right)}{V}
$$

where $W_{v}$ is the rock unit volume of energy consumption and $V$ is the volume of rock samples. 


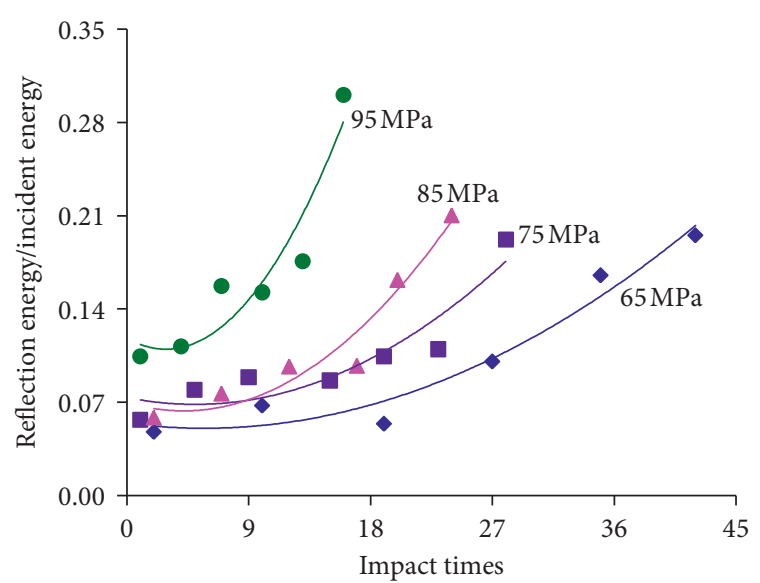

(a)

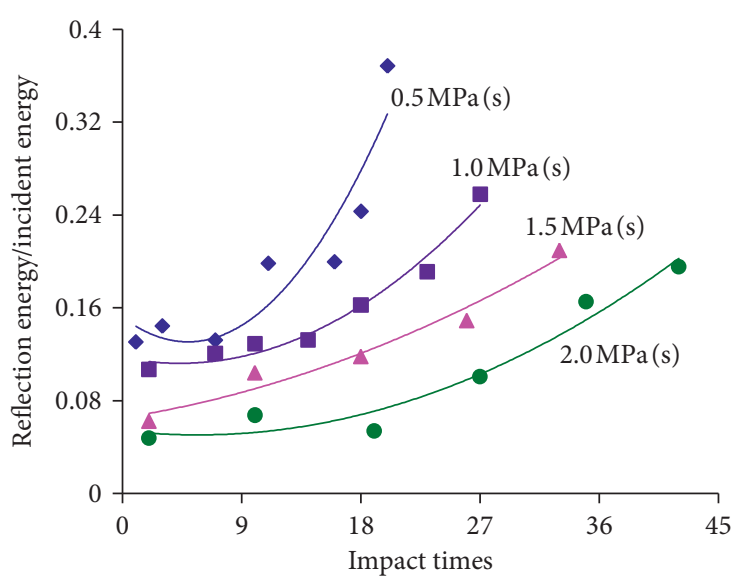

(b)

FIGURE 12: Change law of the ratio of reflection energy to incident energy with the increase of disturbance impact times: (a) unloading rate is 2.0 MPa/s (the numbers in figure represents the preloaded axial static stress of specimen); (b) the preloaded axial pressure is $65 \mathrm{MPa}$ (the number in the figure represents the unloading rate).

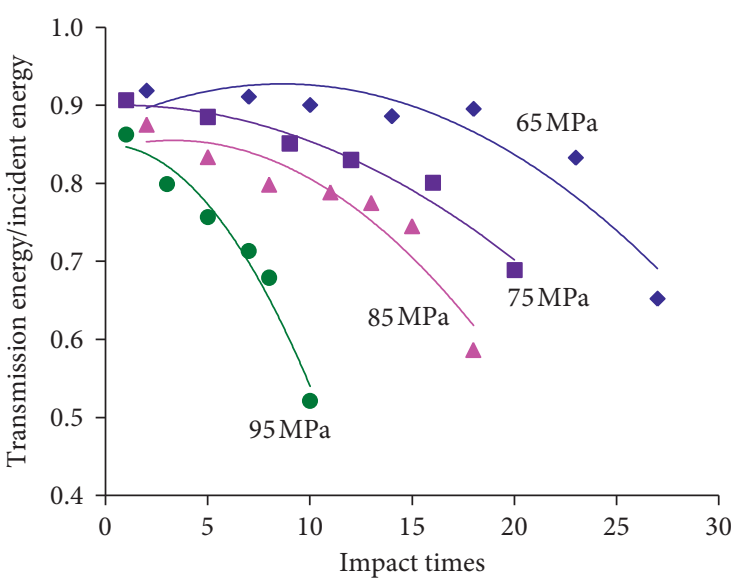

(a)

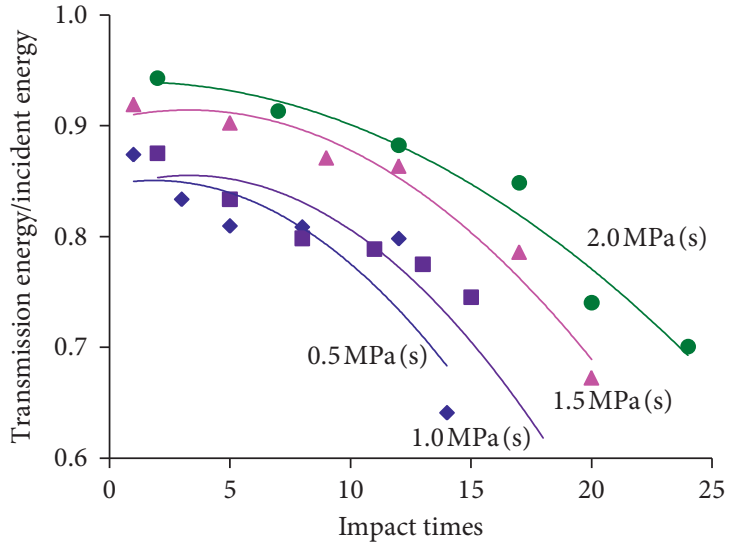

(b)

Figure 13: Change law of the ratio of transmission energy to incident energy with the increase of disturbance impact times: (a) unloading rate is $1.0 \mathrm{MPa} / \mathrm{s}$ (the numbers in figure represents the preloaded axial static stress of specimen); (b) the preloaded axial pressure is $85 \mathrm{MPa}$ (the number in the figure represents the unloading rate).

Figure 14 shows the relationship between the external energy consumed per unit volume of rock sample and the disturbance impact times. As shown in the figure, the energy dissipation per unit volume of rock sample increases with the increase of disturbance impact times. This is because that the damage degree in rock sample gradually increases with the increase of disturbance impact times, and the speed of microcrack germination, propagation, and connection is accelerated gradually, which leads to the gradual increase of energy consumption. At the same time, the energy dissipation of rock samples in the impact process is mainly the transformation of incident energy generated under external impact load, so the difference between incident energy, reflected energy, and transmitted energy gradually increases.

Figure 14(a) shows that the energy dissipation per unit volume of rock decreases with the increase of the preloaded axial pressure when unloading rate remains unchanged. The reason is that the greater the axial preloading is, the more serious the damage that has occurred in the rock sample before the impact load. At this time, the energy consumed by rock sample damage mainly comes from the energy stored in the rock sample under high axial pressure, and the energy provided by the impact load only plays a role in inducing the macroscopic failure acceleration of rock samples. As shown in Figure 14(b), when the preloaded axial pressure is constant, the lower the unloading rate is, the greater the external energy dissipation per unit volume of rock sample is. It is further revealed that the deferring force effect of the unloading process on the external impact load can help to slow down the growth rate of microcracks in the rock sample and indirectly improve the ability of the rock sample to resist the external load.

In order to further analyze the change law of energy dissipation per unit volume of rock under the influence of 


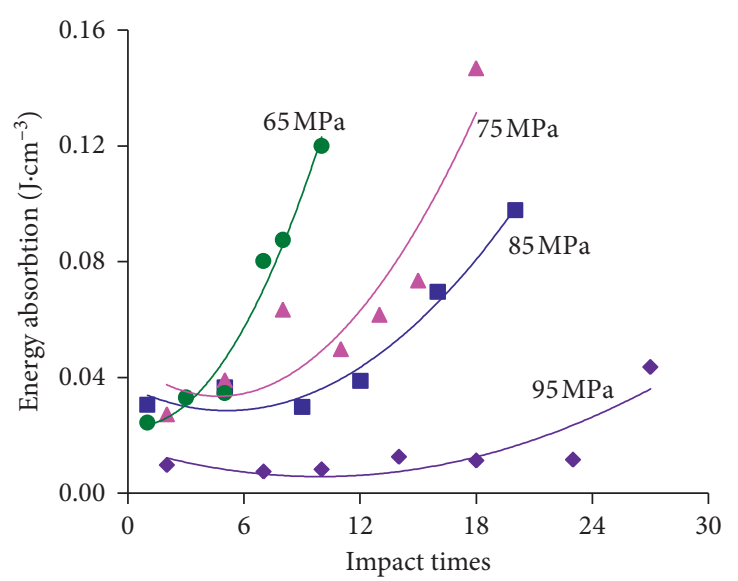

(a)

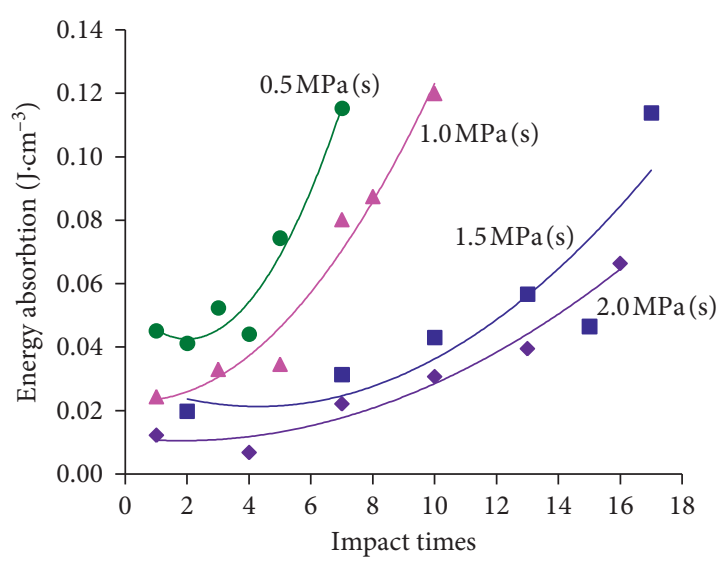

(b)

FIGURE 14: Change law of energy consumption per volume of rock with the increase of disturbance impact times: (a) unloading rate is $1.0 \mathrm{MPa} / \mathrm{s}$ (the numbers in figure represents the preloaded axial static stress of specimen); (b) the preloaded axial pressure is $95 \mathrm{MPa}$ (the number in the figure represents the unloading rate).

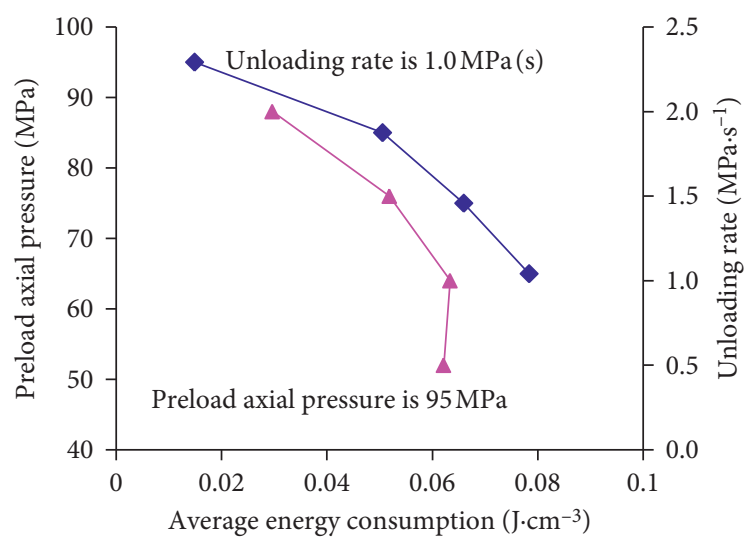

FIGURE 15: Change law of energy consumption per volume of rock under the influence of preloading axial pressure or unloading rate.

preloading axial pressure and unloading rate, the change law of the average energy consumption per unit volume of rock was plotted when the preloaded axial pressure was $95 \mathrm{MPa}$ and the unloading rate was $1.0 \mathrm{MPa} / \mathrm{s}$, as shown in Figure 15. It can be seen from the figure that the average energy consumption per unit volume of rock decreases with the increase of the preloading axial pressure and unloading rate. Before the impact load, the greater the preloaded axial pressure is, the more serious the internal damage of the rock sample will be. At this point, the space in the rock sample for microcrack germination, propagation, and connection development is small, and the impact energy consumed per unit volume of rock is reduced under the impact load of the same strength. Since the unloading process has the effect of delaying force on the impact load, when the unloading rate of axial compression is larger, the effective impact load on rock sample is smaller. As a result, the crack development rate in the rock sample slows down, which is finally reflected in the decrease of energy converted by impact load per unit volume of rock consumption.

\section{Conclusions}

In the process of high static load unloading, the experiment is carried out when skarn is subjected to frequent impact and disturbance, and in order to reveal the internal structure features of skarn, the evolution of rock accompanying energy during impact is studied. The conclusions are as follows:

(1) The dynamic stress-strain curves and its envelope curve have the same trend when rock is subjected to frequent impact and disturbance under high static load unloading, which starts as a short straight segment and then enters the nonlinear development stage and is less affected by the unloading rate. 
(2) With the increase of disturbance impact times, the elastic energy associated with rock increases first and then decreases, while the associated plastic energy, the ratio of reflected energy to incident energy, and the energy consumption per unit volume all increase. As the unloading rate increases, the elastic energy of impact increases gradually, while the plastic energy decreases gradually.

(3) The preloaded high axial pressure aggravates the internal damage of the rock, so that the higher the axial pressure, the bigger the ratio of reflected energy to incident energy, the smaller the ratio of transmitted energy to incident energy, and the smaller the average energy consumption per unit volume of the rock. The unloading rate helps to relieve the impact load, so the larger the unloading rate, the smaller the ratio of reflected energy to incident energy, the larger the ratio of transmitted energy to incident energy, and the smaller the average energy dissipation per unit volume of rock.

(4) Based on the test results, the load bearing capacity of surrounding rock during excavation of deep rock mass project can be predicted by monitoring the change law of internal storage energy of surrounding rock, which provides theoretical reference for stability control of surrounding rock.

\section{Data Availability}

All relevant data are available within the article. The access to the full datasets can be obtained from the corresponding author upon request (wangchun@hpu.edu.cn).

\section{Conflicts of Interest}

The authors declare that they have no conflicts of interest.

\section{Authors' Contributions}

Chun WANG, Mei-zhi Xie, Cheng Wang, and Lu-ping Cheng curated the data; Chun Wang and $\mathrm{Zu}$-qian Xiong were responsible for the funding acquisition; Chun Wang, Mei-zhi Xie, and Cheng Wang wrote the original draft; Chun Wang, Mei-zhi Xie, Zu-qian Xiong, and Lu-ping Cheng wrote, reviewed and edited the article.

\section{Acknowledgments}

This research was funded by the Systematic Project of Guangxi Key Laboratory of Disaster Prevention and Engineering Safety, grant no. 2019ZDK052, National Natural Science Foundation of China, grant no. 51904093, Henan Innovative Science and Technology Team Support Project, grant no. CXTD2017088, Key Laboratory Open Foundation of Henan Polytechnic University, grant no. SJF20180, Key Research and Development and Promotion of Special (Science and Technology) Project of Henan Province, grant no. 192102310247, and Exploration of Youth Innovation Foundation of Henan Polytechnic University, grant no.
NSFRF180321. The support from these agencies is gratefully acknowledged.

\section{References}

[1] M. Cai and E. T. Brown, "Challenges in the mining and utilization of deep mineral resources," Engineering, vol. 3, no. 4, pp. 432-433, 2017.

[2] H. Xie, Y. Ju, F. Gao, M. Gao, and R. Zhang, "Groundbreaking theoretical and technical conceptualization of fluidized mining of deep underground solid mineral resources," Tunnelling and Underground Space Technology, vol. 67, pp. 68-70, 2017.

[3] A. M. Naji, M. Z. Emad, H. Rehman, and H. Yoo, "Geological and geomechanical heterogeneity in deep hydropower tunnels: A rock burst failure case study," Tunnelling and Underground Space Technology, vol. 84, pp. 507-521, 2019.

[4] G. P. Postoev, "The mechanism of block collapse formation upon activizing the deep landslide in terms of dissipative structures," Geoecology . Engineering geology . Hydrogeology . Geocryology, vol. 4, pp. 30-39, 2019.

[5] Q. Jiang, G. Su, X.-t. Feng, G. Chen, M.-z. Zhang, and C. Liu, "Excavation optimization and stability analysis for large underground caverns under high geostress: A case study of the Chinese Laxiwa project," Rock Mechanics and Rock Engineering, vol. 52, no. 3, pp. 895-915, 2019.

[6] Q. Jiang, B. Yang, F. Yan, C. Liu, Y. G. Shi, and L. F. Li, "New method for characterizing the shear damage of natural rock joint based on 3D engraving and 3D scanning," International Journal of Geomechanic, vol. 20, pp. 1-16, 2020.

[7] C. Y. Liu, H. J. Li, and Y. Wu, "Mechanical mechanism and active control technology of rockbursts in Kamchik tunnel," Chinese Journal of Rock Mechanics and Engineering, vol. 39, pp. 961-970, 2020.

[8] B. Y. Jiang, L. G. Wang, S. T. Gu, X. D. Zhang, and W. S. Li, "Study on rockburst mechanism of TBM excavation for deep tunnel based on energy principle," Journal of Mining \& Safety Engineering, vol. 34, pp. 1103-1109, 2017.

[9] M. Zhang, Q. Meng, and S. Liu, "Energy evolution characteristics and distribution laws of rock materials under triaxial cyclic loading and unloading compression," Advances in Materials Science and Engineering, vol. 2017, pp. 1-16, 2017.

[10] Y. Ju, H. Wang, Y. Yang, Q. Hu, and R. Peng, "Numerical simulation of mechanisms of deformation, failure and energy dissipation in porous rock media subjected to wave stresses," Science China Technological Sciences, vol. 53, no. 4, pp. 1098-1113, 2010.

[11] J. Jin, P. Cao, Y. Chen, C. Pu, D. Mao, and X. Fan, "Influence of single flaw on the failure process and energy mechanics of rock-like material," Computers and Geotechnics, vol. 86, pp. 150-162, 2017.

[12] S. D. Duan, Q. Jian, D. P. Xu, and G. F. Liu, "Experimental study of mechanical behavior of interlayer staggered zone under cyclic loading and unloading condition," International Journal of Geomechanic, vol. 20, pp. 1-14, 2020.

[13] X.-q. Zhou, J. Yu, J.-b. Ye, S.-y. Liu, R.-g. Liao, and X.-w. Li, "Complex modeling of the effects of blasting on the stability of surrounding rocks and embankment in water-conveyance tunnels," Complexity, vol. 2018, Article ID 4654315, 19 pages, 2018.

[14] J. B. Zhu, Z. Y. Liao, and C. A. Tang, "Numerical SHPB tests of rocks under combined static and dynamic loading conditions with application to dynamic behavior of rocks under in situ 
stresses," Rock Mechanics and Rock Engineering, vol. 49, no. 10, pp. 3935-3946, 2016.

[15] F. Q. Gong, D. H. Lu, X. L. Liu, and K. Man, "Dynamic characteristics of sandstone at high strain rates and different confining pressures," Disaster Advances, vol. 6, pp. 466-472, 2013.

[16] M. J. Braunagel and W. A. Griffith, "The effect of dynamic stress cycling on the compressive strength of rocks," Geophysical Research Letters, vol. 46, no. 12, pp. 6479-6486, 2019.

[17] K. Liu, Q. B. Zhang, G. Wu, J. C. Li, and J. Zhao, "Dynamic mechanical and fracture behaviour of sandstone under multiaxial loads using a triaxial hopkinson bar," Rock Mechanics and Rock Engineering, vol. 52, no. 7, pp. 2175-2195, 2019.

[18] H. B. Du, F. Dai, Y. Liu, Y. Xu, and M. D. Wei, "Dynamic response and failure mechanism of hydrostatically pressurized rocks subjected to high loading rate impacting," Soil Dynamics and Earthquake Engineering, vol. 129, pp. 1-14, 2020.

[19] G. Duan, J. Li, J. Zhang, E. Assefa, and X. Sun, "Mechanical properties and failure modes of rock specimens with specific joint geometries in triaxial unloading compressive test," Advances in Materials Science and Engineering, vol. 2019, Article ID 1340934, 14 pages, 2019.

[20] Z. Assefa, X. Li, L. Weng, S. Wang, and L. Dong, "Influence of flaw inclination angle on unloading responses of brittle rock in deep underground," Geofluids, vol. 2019, pp. 1-16, 2019.

[21] X. Zhou, Q. Qian, and B. Zhang, "Zonal disintegration mechanism of deep crack-weakened rock masses under dynamic unloading," Acta Mechanica Solida Sinica, vol. 22, no. 3, pp. 240-250, 2009.

[22] T. Luo, S. Wang, C. Zhang, and X. Liu, "Recomendaciones Basadas en el efecto Descarga sobre Los Parámetros De Deterioro De Las Rocas circundantes Durante La excavación De Túneles P+rofundos," Dyna Ingenieria E Industria, vol. 92, no. 1, pp. 648-654, 2017.

[23] Z. H. Zhu, L. Y. Yu, Q. B. Meng, H. W. Jing, H. J. Su, and A. Q. Fu, "Experimental study on dynamic and static characteristics of marble considering pre-peak unloading damage," Chinese Journal of Rock Mechanics and Engineering, vol. 38, pp. 747-756, 2019.

[24] S.-L. Qiu, X.-T. Feng, J.-Q. Xiao, and C.-Q. Zhang, “An experimental study on the pre-peak unloading damage evolution of marble," Rock Mechanics and Rock Engineering, vol. 47, no. 2, pp. 401-419, 2014.

[25] F. K. Xiao, G. Liu, and Q. L. Cheng, "Study on mechanical properties and damage evolution law of secondary destruction induced by simultaneous unloading after the peak of the curve of sandstone," Shock and Vibration, vol. 2018, Article ID 9524248, 18 pages, 2018.

[26] H. Y. Yang, S. G. Gao, G. S Zhou et al., "Dynamic effect and stress wave analysis by transient unloading of a rock sample under high stress condition," Kuwait Journal of Science, vol. 46, pp. 90-102, 2019.

[27] Z.-q. Yin, X.-b. Li, J.-f. Jin, X.-q. He, and K. Du, "Failure characteristics of high stress rock induced by impact disturbance under confining pressure unloading," Transactions of Nonferrous Metals Society of China, vol. 22, no. 1, pp. 175-184, 2012.

[28] K. Peng, Z. Liu, Q. Zou, Q. Wu, and J. Zhou, "Mechanical property of granite from different buried depths under uniaxial compression and dynamic impact: An energy-based investigation," Powder Technology, vol. 362, pp. 729-744, 2020.
[29] X. Liu, Y. Li, F. Zhao, Y. Zhou, W. Wang, and S. Li, "Experimental research on mechanical and energy characteristics of reinforced rock under dynamic loading," Shock and Vibration, vol. 2019, Article ID 4356729, 11 pages, 2019.

[30] P. Ying, Z. M. Zhu, F. Wang, M. Wang, C. Y. Niu, and L. Zhou, "The characteristics of dynamic fracture toughness and energy release rate of rock under impact," Measurement, vol. 147, Article ID 106884, 11 pages, 2019.

[31] M. Lindqvist, "Energy considerations in compressive and impact crushing of rock," Minerals Engineering, vol. 21, no. 9, pp. 631-641, 2008.

[32] Z. Zhou, X. Cai, X. Li, W. Cao, and X. Du, "Dynamic response and energy evolution of sandstone under coupled static-dynamic compression: insights from experimental study into deep rock engineering applications," Rock Mechanics and Rock Engineering, vol. 53, no. 3, pp. 1305-1331, 2020.

[33] X. Cai, Z. Zhou, and X. Du, "Water-induced variations in dynamic behavior and failure characteristics of sandstone subjected to simulated geo-stress," International Journal of Rock Mechanics and Mining Sciences, vol. 130, Article ID 104339, 2020.

[34] D. Y. Li, X. Peng, Z. Y. Han, and Q. Q. Zhu, "Mechanical and failure properties of rocks with a cavity under coupled static and dynamic loads," Engineering Fracture Mechanics, vol. 225, pp. 1-12, 2020.

[35] X. Cai, Z. Zhou, L. Tan, H. Zang, and Z. Song, "Fracture behavior and damage mechanisms of sandstone subjected to wetting-drying cycles," Engineering Fracture Mechanics, vol. 234, Article ID 107109, 2020.

[36] Z. Zang, H. Wang, X. Cai, L. Chen, E. Yude, and R. Cheng, "Damage evolution and failure behavior of post-mainshock damaged rocks under aftershock effects," Energies, vol. 12, no. 23, p. 4429, 2019.

[37] V. Maruvanchery and E. Kim, "Effects of water on rock fracture properties: Studies of mode I fracture toughness, crack propagation velocity, and consumed energy in calcitecemented sandstone," Geomechanics and Engineering, vol. 17, pp. 57-67, 2019.

[38] Y. T. Zhang, X. L. Ding, S. L. Huang, Y. J. Wu, and J. He, "Strength degradation of a natural thin-bedded rock mass subjected to water immersion and its impact on tunnel stability," Geomechanics and Engineering, vol. 21, pp. 63-71, 2020.

[39] J. Yang, L. Li, and H. Lian, "Experimental evaluation of the influences of water on the fracture toughness of mudstones with bedding," Advances in Materials Science and Engineering, vol. 2019, Article ID 5693654, 16 pages, 2019.

[40] X. B. Li, Z. L. Zhou, and W. H. Wang, "Construction of ideal striker for SHPB device based on FEM and neural network," Chinese Journal of Rock Mechanics and Engineering, vol. 24, pp. 4215-4218, 2005.

[41] X.-b. Li, Z.-1. Zhou, and Y.-s. Zhao, "Approach to minish scattering of results for split Hopkinson pressure bar test," Journal of Central South University of Technology, vol. 14, no. 3, pp. 404-407, 2007.

[42] X. Li, Z. Zhou, T.-S. Lok, L. Hong, and T. Yin, "Innovative testing technique of rock subjected to coupled static and dynamic loads," International Journal of Rock Mechanics and Mining Sciences, vol. 45, no. 5, pp. 739-748, 2008.

[43] X. B. Hong and D. S. Gu, Rock Impact Dynamics, Central South University of Technology Press, Changsha, China, 1994.

[44] Y. F. Wang, X. J. Zheng, H. Z. Jiao, F. B. Cheng, and H. B. Zhao, "Energy evolution mechanism and energy yield 
criterion in granite's failure process," Explosion and Shock Waves, vol. 36, pp. 876-882, 2016.

[45] Z. Z. Zhang and F. Gao, "Experimental investigations on energy evolution characteristics of coal, sandstone and granite during loading process," Journal of China University of Mining \& Technology, vol. 44, pp. 416-422, 2015. 